Research

\title{
Effects of alternative bedding substrates on lamb welfare, productive performance, and meat quality during the finishing phase of fattening
}

\author{
Dayane Lemos Teixeira ${ }^{\mathrm{a}, *}$, Genaro Miranda-de la Lama ${ }^{\mathrm{b}}$, Morris Villarroel ${ }^{\mathrm{c}}$,

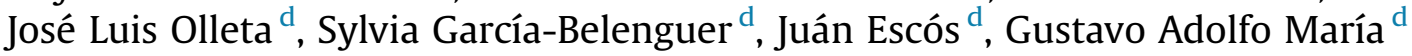 \\ a Pig Development Department, Animal \& Grassland Research \& Innovation Centre, TEAGASC Moorepark, Fermoy, Republic of Ireland \\ ${ }^{\mathrm{b}}$ Department of Food Science, Metropolitan Autonomous University, Lerma, Mexico \\ ${ }^{\mathrm{c}}$ Department of Animal Science, E.T.S.I.A. Polytechnic University of Madrid, Madrid, Spain \\ ${ }^{\mathrm{d}}$ Department of Animal Production and Food Science, Faculty of Veterinary Science, University of Zaragoza, Zaragoza, Spain
}

\section{A R T I C L E I N F O}

Article history:

Received 16 August 2013

Received in revised form

24 November 2014

Accepted 31 December 2014

Available online 8 January 2015

\section{Keywords:}

bedding substrates

welfare

social behaviors

stereotypies

meat quality

\begin{abstract}
A B S T R A C T
The study analyzed the effect of using sawdust, cellulose, straw, and rice husk bedding on the welfare, performance and meat quality of lambs during the finishing phase of fattening. Ninety-six lambs (fed ad libitum with concentrate) were assigned to pens containing 1 of 4 bedding materials in groups of 12 for 14 days. Live weight and feed consumption were recorded to estimate daily gain and conversion index, and carcass and meat quality variables were measured. Stereotypies, exploratory interactions with bedding material, and agonistic and affiliative interactions between animals were recorded by continuous sampling techniques using video recording. The substrates affected behavior and stress response variables. There were more stereotypies and agonistic interactions at the beginning of the experiment in all treatments $(P \leq 0.05)$. The lambs fattened on cellulose bedding interacted more with the substrate throughout the finishing stage $(P \leq 0.05)$, where there were also more affiliative interactions $(P \leq 0.05)$. Stress levels were lower in lambs on straw, followed by cellulose. No significant differences in production or carcass and meat quality traits were observed between treatments. The results suggest that all substrates evaluated could be efficiently incorporated into the system as bedding material without affecting productivity or product quality.
\end{abstract}

(C) 2015 Elsevier Inc. All rights reserved.

\section{Introduction}

Intensive production systems with barren environments may cause chronic stress, which impairs the efficiency of feed utilization and results in significantly reduced growth rates (Swanson, 1995). The absence of environmental stimuli also produces behavioral changes, which may indicate reduced welfare (Tuyttens, 2005). One approach to solve confinement-related problems in intensive production systems involves the manipulation of the animals' environment to suit

\footnotetext{
* Address for reprint requests and correspondence: Dayane Lemos Teixeira, Department of Animal Production and Food Science, Faculty of Veterinary Science, University of Zaragoza, Miguel Servet 177, Zaragoza 50013, Spain, Tel: 34 976761000x2490; Fax: 34976761612.

E-mail address: dadaylt@hotmail.com (D.L. Teixeira).
}

their needs (Swanson, 1995). Providing good bedding can be an important way to enrich the environment in intensive systems.

Bedding should be sufficiently comfortable, dry, and soft to ensure that the animals have appropriate resting space and can perform behaviors that guarantee their welfare and productivity (Tuyttens, 2005; Norring et al., 2010). The most traditionally used bedding is cereal straw, which also serves as forage (Teixeira et al., 2012). Straw is a major by-product from agricultural fields and is currently the most frequently used bedding material in Europe (Ericsson and Nilsson, 2006). The use of straw bedding in lamb housing has a number of benefits for lamb welfare, providing comfort, encouraging the ontogeny of natural behavior, and consequently, the lamb's welfare (Teixeira et al., 2012). However, the use of straw as bedding has some disadvantages as it increases production costs (e.g., the cost of straw itself, increased labor, transport, and storage), is incompatible with liquid manure 


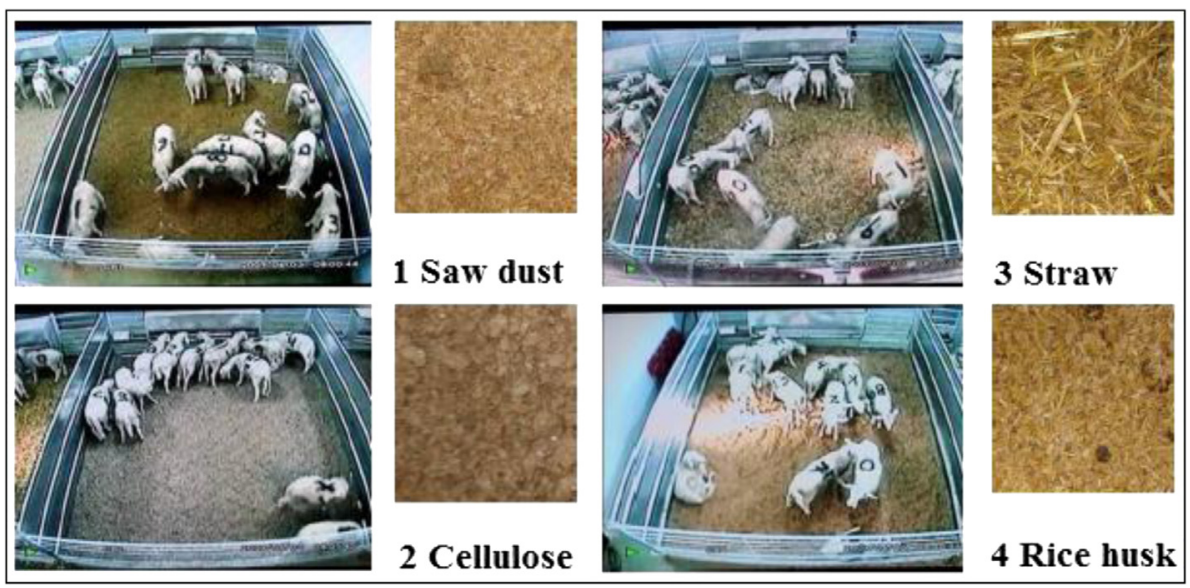

Figure 1. The lambs were housed on 1 of 4 bedding substrates: sawdust (1), cellulose (2), straw (3), and rice husk (4).

handling systems, (Tuyttens, 2005) and quickly loses chemical and microbiological characteristics after use (Teixeira et al., 2014).

Experts in farm animal welfare assign considerable importance to the availability of a substrate such as straw in the assessment of housing systems (Spoolder et al., 2003). In the European context, straw can be a high-cost bedding material in pastoral regions without arable cropping, and the rising cost of haulage and alternative uses for arable by-products can exacerbate this problem (Teixeira et al., 2012). The demand of straw as organic material to amend soils to ensure sustainable crop production and the use of straw as a source of biomass for energy production may be 2 other reasons for the increase in the cost of straw as bedding or forage in intensive lamb meat systems (Gauder et al., 2011). Consequently, as straw costs could potentially increase further, the lamb meat industry is seeking alternative bedding materials. System managers require clear guidance and information on the suitability of potential alternative bedding materials and their effect on the welfare, performance and meat quality of their animals, as well as the cost of using them. In our study, in addition to straw, we analyzed 3 substrates that are relatively frequent in the Aragón region of Spain, sawdust, rice husk, and a by-product of cellulose (LER-030310, a byproduct of the paper industry). The aim of our study was to evaluate the effect of using 3 alternative bedding materials other than straw, on lamb welfare, productive performance, and meat quality during the fattening phase.

\section{Material and methods}

The study was carried out at the experimental farm of the University of Zaragoza, Spain (latitude $41^{\circ} 41^{\prime} \mathrm{N}$ ), between May and June and with a 1-week interval between replicates. The area is located in the Ebro River depression, characterized by a dry Mediterranean climate with an average annual temperature of $15^{\circ} \mathrm{C}$ and an average $317 \mathrm{~mm}$ annual rainfall. All protocols were approved by the Animal Experimentation Ethics Committee of the University of Zaragoza.

\section{Animals and treatments}

A total of 96 clinically healthy, entire male lambs of the Rasa Aragonesa breed were assigned to 2 consecutive replicates. Average live weight on arrival to the feedlot classification centre was $19.11 \pm$ $1.07 \mathrm{~kg}$, and lambs were approximately 80 days old. In each replicate, 48 animals were kept in a holding pen with solid floor during 24 hours after arrival to the experimental unit, placed randomly into 1 of 4 groups (12 lambs each) and fattened for 14 days (finishing phase). In the original farm and holding pen, all animals had been reared on a solid floor, without any bedding. All animals were individually marked with numbers on their sides and backs with black livestock paint spray. Each group of 12 lambs was housed in $2.9 \times$ $3.7 \mathrm{~m}$ pens (stocking density $0.90 \mathrm{~m}^{2}$ per lamb) with 1 of 4 alternative bedding materials: sawdust, cellulose (the substrate that meant the industrial waste of paper and pulp. The Spanish registered code is LER-030310), straw, and rice husk (Figure 1). All pens had a similar size and bedding material was always 10 -cm deep at the beginning of each trial. The cellulose was delivered baled, and the other substrates were delivered loose in bulk. The amount of each bedding material (expressed in $\left.\mathrm{kg} / \mathrm{m}^{2}\right)$ used to cover the floor $(10-\mathrm{cm}$ thick) in each treatment was weighed. The costs of bedding material (retail price $/ \mathrm{kg}$ ) were $€ 0.15$ for sawdust, $€ 0.05$ for cellulose, $€ 0.06$ for straw, and $€ 0.055$ for rice husk at the time of the study. No fresh bedding material was provided during the experiment.

All groups were fed ad libitum with pellet concentrate in a feeder, as well as with fresh water in a drinker bowl. The commercial concentrate (Ovirum High Energy, Oviarago'n Alimentos, Zaragoza, Spain) contained barley, corn, wheat, vegetable fat, soyderived products, sugarcane molasses, calcium carbonate, sodium chloride, and a vitamin mineral corrector ( $18 \%$ crude protein and $3.5 \mathrm{Mcal} / \mathrm{kg}$ dry matter/day of metabolizable energy). Following the commercial protocol, animals were electrically stunned and slaughtered in a European Union-approved slaughterhouse using standard commercial procedures after which instrumental meat quality was analyzed.

\section{Behavioral measures}

A video recording device (model VDVR-9, Circontrol S.A., Terrassa, Spain) was set up in a room close to the pens to record behavior. One camera was placed in front of each pen, $220 \mathrm{~cm}$ above the ground. Continuous behavior sampling was recorded for 12 hours a day ( 8 AM-8 PM) on days 1,8 , and 12 . Each video was observed by the same trained observer based on continuous behavior sampling (Martin and Bateson, 1993) to record the frequency of stereotypies, bedding interactions, and agonistic and affiliative interactions between animals (Table 1).

\section{Physiological measures}

Blood samples were taken by jugular venipuncture after behavioral observations on days 1 and 8 (two 10-mL tubes were collected per animal, with and without anticoagulant, EDTA-K3). 
Table 1

Description of behaviors collected during observations

\begin{tabular}{|c|c|}
\hline Behaviors & Description \\
\hline Stereotypies & $\begin{array}{l}\text { Repetitive and seemingly functionless oral and oronasal } \\
\text { activities (including licking or gnawing feeders, walls, fences, } \\
\text { wood, and metal), if perceived as such (according } \\
\text { to Mason and Rushen, 2008) }\end{array}$ \\
\hline $\begin{array}{l}\text { Bedding } \\
\quad \text { interactions }\end{array}$ & Nuzzling or scratching the substrate \\
\hline \multicolumn{2}{|l|}{ Agonistic } \\
\hline Butts & Using its forehead to hit another lamb on any part of its body \\
\hline Pushes & $\begin{array}{l}\text { Using its body to push another lamb to access the feeder or } \\
\text { water trough }\end{array}$ \\
\hline Mounting & $\begin{array}{l}\text { Mounting another lamb from behind to move the latter, } \\
\text { without an apparent sexual function }\end{array}$ \\
\hline Kicking & Hitting another lamb on any part of its body, with its forelegs \\
\hline Threats & $\begin{array}{l}\text { Turning toward or approached another lamb with its head } \\
\text { down and then lunged, without contact }\end{array}$ \\
\hline $\begin{array}{r}\text { Displacing } \\
\text { another }\end{array}$ & $\begin{array}{l}\text { Moving toward another lamb, causing the latter to walk or } \\
\text { run away }\end{array}$ \\
\hline \multicolumn{2}{|r|}{ 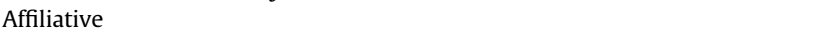 } \\
\hline Rubbing & Rubbing another lamb \\
\hline Nibbling & Grooming another lamb's body using its teeth \\
\hline Licking & Licking the body of another lamb \\
\hline Sniffing & Sniffing the body of another lamb \\
\hline
\end{tabular}

The ethogram was based on the study by Teixeira et al. (2012).

Animal handling and venipuncture required $<15$ minutes per group. Samples were kept on ice for $<1$ hour and taken to the laboratory for routine hematologic measurements. The EDTA plasma and serum were centrifuged at $1509 \mathrm{~g}$ for 10 minutes and aliquots were frozen and kept at $-30^{\circ} \mathrm{C}$ until analyzed. An automatic particle counter (Microcellcounter F-800 and Auto dilutor AD-260, by Sysmex) was used to count red blood cells and white blood cells (number per $\mathrm{mm}^{3}$ ), hemoglobin $(\mathrm{g} / \mathrm{dL})$, and hematocrit (\%). The leukocyte formula was estimated from blood swabs on clean slides. Staining was performed by the rapid panoptic method using dyes from Química Clínica Aplicada Inc.. With an optic immersion microscope (Axiolab re, Carl Zeiss), we counted and identified 100 leucocytes per sample (neutrophils, lymphocytes, eosinophils, basophils, and monocytes).

The plasma concentration of cortisol was determined (sample with EDTA-K3) by enzyme immunoassay using an "in-house kit" (Chacón et al., 2004). Each sample was determined in duplicate from $50 \mathrm{~mm}^{3}$ of plasma and the results were expressed in $\mathrm{ng} / \mathrm{nL}$ with the corresponding controls. Serum concentrations of glucose $(\mathrm{mg} / \mathrm{dL})$ and nonesterified fatty acid (NEFA; nmol/L) and the activity of creatine kinase (CK; UI/I) were analyzed by a multianalyzer ACE (clinical chemistry system of Alfa Wasserman), with commercial kits (Glucose Ref. AE2-17; NEFA C Ref. 994-75409 of Wako and CK NAC Ref. AE1-13, respectively). The concentration of lactate was determined using a Sigma Diagnostic kit (lactate no 735-10) and spectrophotometer (Lambda 5, PerkinElmer), and the results were expressed in $\mathrm{mg} / \mathrm{dL}$.

\section{Table 2}

Technoeconomic indicators of each bedding substrate used to finish 12 lambs in 1 pen of $10.73 \mathrm{~m}^{2}$

\begin{tabular}{|c|c|c|c|c|}
\hline \multirow[t]{2}{*}{ Variables } & \multicolumn{4}{|c|}{ Bedding substrates } \\
\hline & Sawdust & Cellulose & Straw & Rice husk \\
\hline Amount $\left(\mathrm{kg} / \mathrm{m}^{2}\right)$ & 8.41 & 5.24 & 1.62 & 4.36 \\
\hline Total amount (kg) & 90.24 & 56.25 & 17.38 & 46.78 \\
\hline Availability in Spanish market & $\mathrm{L}$ & $\mathrm{M}$ & $\mathrm{H}$ & $\mathrm{MH}$ \\
\hline Price $(€ / \mathrm{kg})$ & 0.15 & 0.05 & 0.06 & 0.055 \\
\hline Total finishing costs $(€)$ & 13.54 & 2.81 & 1.04 & 2.57 \\
\hline Impact $(\%)$ on lamb price (60 €) & 1.8 & 0.04 & 0.01 & 0.03 \\
\hline
\end{tabular}

$\mathrm{H}$, high availability; L, low availability; $\mathrm{M}$, medium availability; $\mathrm{MH}$, medium or high availability.
Productive performance and meat quality

Fasted animals were weighed individually at the beginning of the experimental period (W1) and just before transport to the slaughterhouse (W2). The overall average slaughter live weight was 22.54 $\pm 0.35 \mathrm{~kg}$, within the Ternasco-type category (Sañudo et al., 1996). Concentrates were weighed into the feeder, and feed remaining in the feeder at the end of the experiment was weighed out. We estimated the total consumption of concentrate (CO) as the difference between the concentrate added and the concentrate refused. Average daily gain was estimated as the difference between W2 and W1 (WG) divided by the total fattening days (14). The conversion index was estimated as CO/WG. The animals were slaughtered at an European Union-approved abattoir located in the city of Zaragoza. After overnight lairage in pens with cemented walls and nonskid floors (water available but no food), lambs were electrically stunned and dressed using standard commercial procedures.

After dressing, the carcasses entered a freezing tunnel that led to a chill room kept at $2^{\circ} \mathrm{C}-3^{\circ} \mathrm{C}$, with an air velocity of $0.5 \mathrm{~m} / \mathrm{s}$ until 24 hours postmortem, after which cold carcasses were weighed. The chilling system complied with the quality certification GS1 standard AECOC (http://www.aecoc.es). Carcasses were classified using the EUROP classification scale for conformation (CONF; E, excellent; U, very good, R, good; O, fair; P, poor), scoring from 15 for $\mathrm{E}+$ to 1 for $\mathrm{P}$-. For the fat cover classification (1, low; 2 , slight; 3 , average; 4 , high; 5 , very high) the score was 15 for $5+$ very high to 1 for 1 - (European Union, 1993). The extent of bruising on the carcasses was estimated visually. Each carcass received a score of 0 (no bruising), 1 (slight bruising), 2 (moderate bruising), or 3 (high bruising).

After chilling for 24 hours, the longissimus muscle was removed and after 1 hour of oxygenation, a portable $\mathrm{pH}$ meter (fitted with a penetration electrode 52-00 from Crison Instruments, Barcelona, Spain) was used, which was inserted into a small incision in the right loin (L2-L3 vertebrae) to determine $\mathrm{pH} 24$ hours postmortem $\left(\mathrm{pH}_{\mathrm{ult}}\right)$. The $\mathrm{pH}$ meter was recalibrated at the same temperature of the room $\left(5^{\circ} \mathrm{C}\right)$ after every 5 samples using 2 standard buffer solutions at $\mathrm{pH} 7.0$ and 4.0. The meat color was estimated with a Minolta CR-200b, following the CIE L*a*b* system (CIE, 1976). The color of fresh meat was measured on the cut surface of the middle section. The colorimetric indices of chromaticity $\left\{C^{*}=\left[\left(a^{2}+b^{2}\right)^{1 / 2}\right]\right.$, quantity of color $\}$ and hue $\left[h^{*}=1 / \tan \left(b^{*} / a^{*}\right)\right.$, real color] were calculated. Final values were the average of 3 measurements.

\section{Statistical analysis}

Data were analyzed using SAS/STAT (9.1 SAS Inst. Inc., Cary, NC, USA) by SAS (1988). Data were tested for normality before analysis by examination of box and normal distribution plots and transformed when necessary. The behavior data observed as a continuous sampling were transformed by the square root function. These behaviors (average per animal per day) and physiology were analyzed using PROC MIXED with repeated measurements (day) and treatment as the fixed effects and the lamb as the random effect. The original full model included the effect of replicate, which was found to be nonsignificant and consequently was dropped from the model. Least square means of the number of behaviors are expressed per day and per animal. Production and meat quality data were analyzed using the least square methodology of the GLM procedure of SAS (SAS, 1988), fitting a 1-way model with a fixed effect of type of substrate (4 levels). The general representation of the model used was: $y=X b+e$, where $y$ was an $\mathrm{N} \times 1$ vector of records, $b$ denoted the fixed effect in the model with the association matrix $X$, and $e$ was the vector of residual effects. For meat variables, the model was covariated with cold carcass weight. Least square 


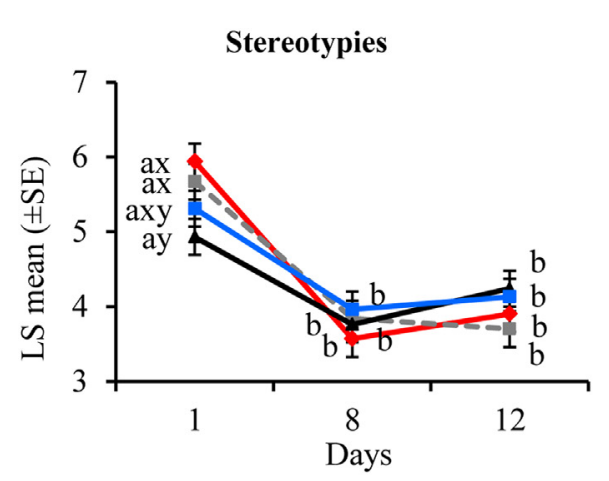

Agonistic interactions

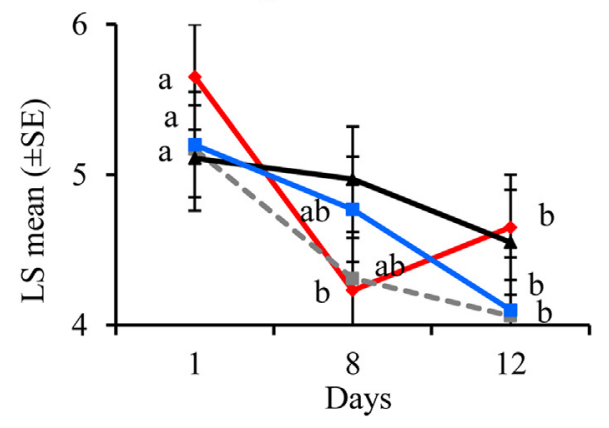

Bedding interactions

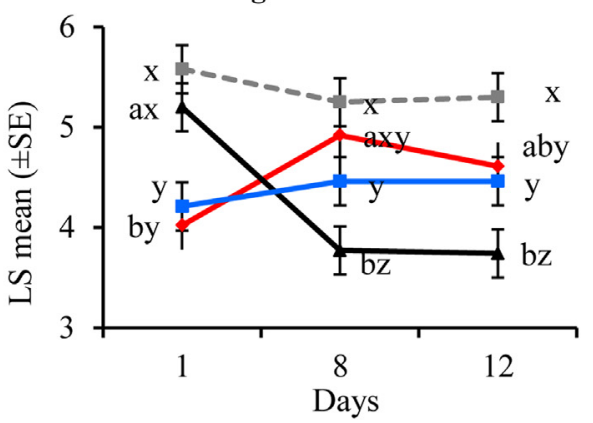

Affiliative interactions

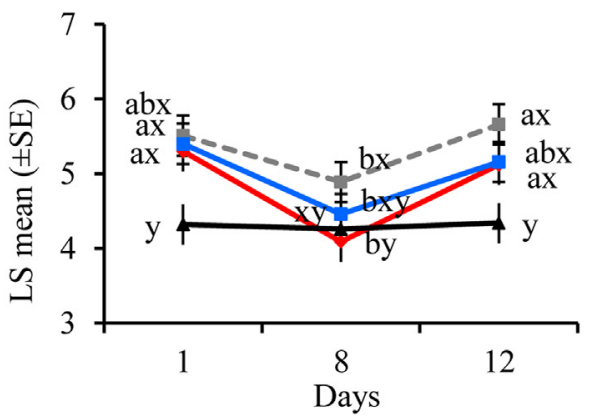

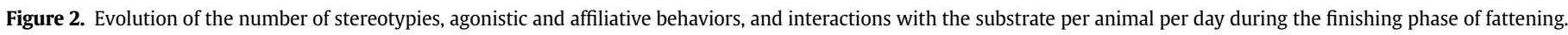

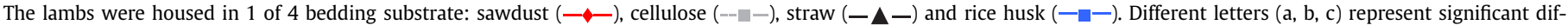
ferences $(P<0.05)$ between days within treatment. Different letters $(\mathrm{x}, \mathrm{z})$ represent significant differences $(P<0.05)$ between treatments within day.

means are reported throughout and the probability of obtaining values $\leq 0.05$ was deemed to be statistically significant.

\section{Results}

\section{Economic aspects}

The amount of each bedding material (expressed in $\mathrm{kg} / \mathrm{m}^{2}$ ) used to cover the floor (10-cm thick) is presented in Table 2 , as are the estimated costs, calculated using the commercial prices of each substrate $(€ / \mathrm{kg})$. Considering the total amount of each bedding material used in each pen, the sawdust bedding was clearly the most expensive substrate. Straw bedding was the cheapest substrate, being 13 times cheaper than sawdust. The cost of cellulose and rice husk was similar and around double of the price of straw bedding.

\section{Behavioral measures}

The least square means \pm standard error of the square root of the number of interactions with the bedding material, agonistic and affiliative interactions between animals, as well as the stereotypic behaviors observed per day and per animal are presented in Figure 2 . The use of different types of bedding significantly affected the frequency of the lamb behavior $(P \leq 0.05)$. A significant effect was also observed for sampling day in each treatment $(P \leq 0.05)$. No significant differences were found regarding the frequency of stereotypic behaviors between treatments on days 8 and 12; however, the lambs on sawdust and cellulose substrate performed more stereotypies than the animals on straw on day 1 . There was a high frequency of stereotypic behaviors at the beginning of the experiment in all treatments. On days 8 and 12 of fattening, the levels of stereotypic behaviors decreased considerably in all 4 treatments $(P \leq 0.05)$.
In general, the lambs fattened on cellulose bedding interacted more with the substrate throughout the finishing stage. On day 1, lambs on cellulose bedding and straw interacted significantly more $(P \leq 0.05)$ with the bedding substrate than sawdust or rice husk. No differences between these 2 last substrates were observed. Throughout the finishing stage, animals on cellulose explored the bedding more often. Lambs interacted more with the sawdust bedding on day 8 compared to day $1(P \leq 0.05)$. However, with straw, interaction decreased during the finishing period $(P \leq 0.05)$.

With the exception of the animals on straw bedding, agonistic interactions showed a very similar pattern to that of stereotypic behavior, that is, there were more at the beginning of finishing and they gradually decreased $(P \leq 0.05)$. Affiliative interactions were practically constant in lambs on straw bedding. In the case of the other 3 substrates, a descendant-ascendant pattern was observed with a low point on day 8 . Consequently, it was observed that interactions that were interpreted as affiliative were significantly higher on days 1 and 12 in lambs on straw than in the lambs on the other 3 beddings $(P \leq 0.05)$.

\section{Physiological measures}

Table 3 shows the least square means \pm standard error for plasma and hematologic indicators of welfare of the lambs fattened on each bedding material. In the conditions in which our study was performed, bedding substrate appears to affect some variables during adaptation to the finishing phase of fattening. On both blood sampling days, the concentration of plasma cortisol was lower in animals on straw than on sawdust. Lactate concentration was lowest on day 8 with lambs on sawdust compared with the other 3 treatments. On day 1, lactate was lowest in lambs on cellulose compared with those on sawdust or straw. Glucose levels were highest on day 1 in lambs on straw compared to those on cellulose and rice husk. No differences were detected in NEFA concentrations. 
Table 3

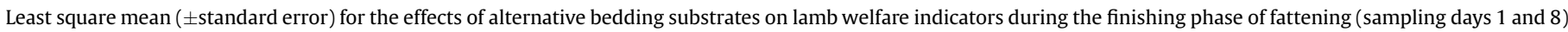

\begin{tabular}{|c|c|c|c|c|c|}
\hline \multirow[t]{2}{*}{ Variables } & \multirow[t]{2}{*}{ Day } & \multicolumn{4}{|l|}{ Bedding substrates } \\
\hline & & Sawdust & Cellulose & Straw & Rice husk \\
\hline \multirow[t]{2}{*}{ Cortisol (ng/mL) } & 1 & $14.86 \pm 1.71 \mathrm{x}$ & $10.56 \pm 1.71 x y$ & $9.65 \pm 1.71 y$ & $10.87 \pm 1.71 x y$ \\
\hline & 8 & $15.25 \pm 1.71 \mathrm{x}$ & $11.74 \pm 1.71 x y$ & $9.75 \pm 1.71 \mathrm{y}$ & $11.76 \pm 1.75 x y$ \\
\hline \multirow[t]{2}{*}{ Lactate $(\mathrm{mg} / \mathrm{dL})$} & 1 & $20.04 \pm 2.28 x$ & $12.77 \pm 2.23$ ay & $22.22 \pm 2.23 x$ & $17.46 \pm 2.23 x y$ \\
\hline & 8 & $16.17 \pm 2.23 y$ & $22.74 \pm 2.23 b x$ & $18.24 \pm 2.23 x$ & $17.69 \pm 2.28 x$ \\
\hline \multirow[t]{2}{*}{ Glucose $(\mathrm{mg} / \mathrm{dL})$} & 1 & $112.58 \pm 5.58 x y$ & $107.13 \pm 5.58 y$ & $124.25 \pm 5.58 \mathrm{ax}$ & $108.17 \pm 5.58 y$ \\
\hline & 8 & $115.00 \pm 5.58$ & $110.00 \pm 5.58$ & $107.13 \pm 5.58 b$ & $110.70 \pm 5.57$ \\
\hline \multirow[t]{2}{*}{ NEFA (nmol/L) } & 1 & $0.07 \pm 0.01$ & $0.11 \pm 0.01 \mathrm{a}$ & $0.08 \pm 0.01$ & $0.10 \pm 0.01$ \\
\hline & 8 & $0.08 \pm 0.01$ & $0.06 \pm 0.01 b$ & $0.06 \pm 0.01$ & $0.06 \pm 0.01$ \\
\hline \multirow[t]{2}{*}{ CK (UI/L) } & 1 & $171.42 \pm 17.68 \mathrm{a}$ & $179.17 \pm 17.68$ & $137.46 \pm 17.68$ & $165.08 \pm 17.68$ \\
\hline & 8 & $117.50 \pm 17.68 b$ & $155.04 \pm 17.68$ & $98.71 \pm 17.68$ & $139.52 \pm 18.06$ \\
\hline \multirow[t]{2}{*}{ Ratio N/L } & 1 & $0.57 \pm 0.10 y$ & $0.85 \pm 0.10 a x$ & $0.67 \pm 0.10 x y$ & $0.48 \pm 0.10 \mathrm{y}$ \\
\hline & 8 & $0.49 \pm 0.10$ & $0.54 \pm 0.10 \mathrm{~b}$ & $0.59 \pm 0.10$ & $0.58 \pm 0.10$ \\
\hline \multirow[t]{2}{*}{$\mathrm{WBC}\left(10^{3} / \mathrm{mm}^{3}\right)$} & 1 & $6.80 \pm 0.87$ & $6.54 \pm 0.90$ & $6.84 \pm 0.87$ & $7.61 \pm 0.87$ \\
\hline & 8 & $6.07 \pm 0.61$ & $6.84 \pm 0.64$ & $7.46 \pm 0.63$ & $6.52 \pm 0.61$ \\
\hline \multirow[t]{2}{*}{$\mathrm{RBC}\left(10^{6} / \mathrm{mm}^{3}\right)$} & 1 & $9.95 \pm 0.25 a$ & $10.41 \pm 0.26$ & $10.50 \pm 0.25$ & $10.79 \pm 0.25$ \\
\hline & 8 & $10.87 \pm 0.17 b$ & $10.27 \pm 0.18$ & $10.31 \pm 0.18$ & $10.62 \pm 0.17$ \\
\hline \multirow[t]{2}{*}{ HTO (\%) } & 1 & $30.55 \pm 0.94$ ay & $32.91 \pm 0.98 x y$ & $32.67 \pm 0.94 x y$ & $34.88 \pm 0.94 x$ \\
\hline & 8 & $33.33 \pm 0.66 b$ & $31.91 \pm 0.69$ & $32.21 \pm 0.68$ & $33.35 \pm 0.66$ \\
\hline \multirow[t]{2}{*}{ HAEM (g/dL) } & 1 & $10.94 \pm 0.22 x$ & $10.55 \pm 0.22 x y$ & $10.07 \pm 0.22 y$ & $10.68 \pm 0.22 x$ \\
\hline & 8 & $10.99 \pm 0.15 x$ & $10.39 \pm 0.16 y$ & $10.26 \pm 0.16 y$ & $10.54 \pm 0.15 y$ \\
\hline
\end{tabular}

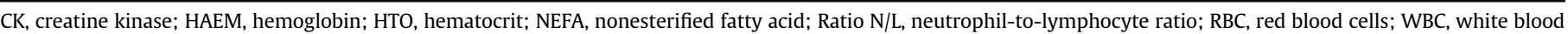
cells.

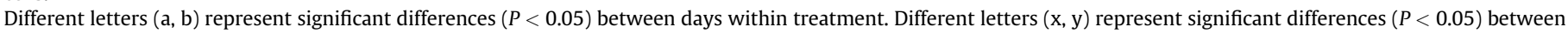
treatments within day.

The enzymatic activity of CK was slightly higher at the start of the experiment, particularly in lambs fattened on sawdust bedding. With regard to the $\mathrm{N} / \mathrm{L}$ ratio, no differences were detected between treatments by day 8 of the trial; however, at the start of the experiment, the lambs on cellulose bedding had a significantly higher ratio $(P \leq 0.05)$ compared with the lambs fattened on sawdust or rice husk. This difference was not detected when compared with the lambs on straw bedding, which also had a slightly higher N/L ratio. No differences were detected for white and red blood cells between treatments on either of the sample days, except for lambs on sawdust, which had more red blood cells on day 8 compared to day 1 . At the beginning of the experiment, hematocrit values were higher in lambs on rice husk bedding compared with the lambs on sawdust bedding; however, those differences disappeared halfway through the experiment. Nevertheless, in the lambs on sawdust bedding, an increase in hematocrit values was

\section{Table 4}

Least square mean ( \pm standard error) for the effects of alternative bedding substrates on production traits and meat quality variables during the finishing phase of fattening

\begin{tabular}{lrrrr}
\hline Variables & \multicolumn{1}{l}{ Sawdust } & \multicolumn{1}{l}{ Cellulose } & \multicolumn{1}{l}{ Straw } & \multicolumn{1}{l}{ Rice husk } \\
\hline Initial weight $(\mathrm{kg})$ & $19.00 \pm 0.32$ & $19.19 \pm 0.31$ & $18.89 \pm 0.32$ & $19.00 \pm 0.32$ \\
Final weight $(\mathrm{kg})$ & $22.81 \pm 0.34$ & $22.78 \pm 0.35$ & $22.22 \pm 0.35$ & $22.35 \pm 0.36$ \\
Average daily & $0.27 \pm 0.02$ & $0.28 \pm 0.02$ & $0.26 \pm 0.02$ & $0.26 \pm 0.02$ \\
$\quad$ gain (g) & & & & \\
Conversion & $4.14 \pm 0.31$ & $3.61 \pm 0.31$ & $4.15 \pm 0.32$ & $3.76 \pm 0.33$ \\
$\quad$ index (kg) & & & & \\
Carcass weight $(\mathrm{kg})$ & $10.45 \pm 0.18$ & $10.51 \pm 0.18$ & $10.28 \pm 0.18$ & $10.55 \pm 0.19$ \\
Bruising (0-3) & $0.54 \pm 0.17$ & $0.61 \pm 0.17$ & $0.27 \pm 0.17$ & $0.57 \pm 0.18$ \\
Conformation score & $4.37 \pm 0.33$ & $5.17 \pm 0.33$ & $4.54 \pm 0.34$ & $4.28 \pm 0.35$ \\
Fat cover score & $4.21 \pm 0.25$ & $4.04 \pm 0.25$ & $3.95 \pm 0.26$ & $4.43 \pm 0.27$ \\
pH ${ }_{24}$ & $5.66 \pm 0.02$ & $5.63 \pm 0.02$ & $5.65 \pm 0.02$ & $5.68 \pm 0.02$ \\
Color & & & & \\
$\quad L^{*}($ lightness) & $43.85 \pm 0.66$ & $43.70 \pm 0.67$ & $43.95 \pm 0.66$ & $43.08 \pm 0.67$ \\
$\quad$ a* (redness) & $16.67 \pm 0.42$ & $16.53 \pm 0.43$ & $16.83 \pm 0.42$ & $17.11 \pm 0.43$ \\
$\quad b^{*}($ yellowness) & $7.14 \pm 0.23$ & $7.01 \pm 0.23$ & $7.31 \pm 0.23$ & $7.34 \pm 0.23$ \\
Chromaticity & $18.14 \pm 0.46$ & $17.97 \pm 0.48$ & $18.36 \pm 0.46$ & $18.63 \pm 0.48$ \\
$\quad\left(a^{2}+b^{2}\right)^{1 / 2}$ & & & & \\
Hue $1 /$ TAN $\left(b^{*} / a^{*}\right)$ & $23.15 \pm 0.42$ & $23.03 \pm 0.43$ & $23.42 \pm 0.42$ & $23.18 \pm 0.43$ \\
\hline
\end{tabular}

recorded between days 1 and 8 . At the start of the experiment, the lambs fattened on sawdust and rice husk bedding showed significantly higher hemoglobin values than those on straw; however, by day 8 of the study, only the lambs on sawdust bedding kept high values for this variable.

\section{Productive performance and meat quality}

The least square means \pm standard error for productive performance and quality variables of the carcass and meat of lambs fattened on 4 types of bedding substrates are listed in Table 4. In general, all the treatments revealed productivity and quality values that came within the expected ranges for this type of commercial lamb. Under our study conditions, we did not find any significant effects of substrate type on these variables, which are of great relevance for the efficiency of the production system.

\section{Discussion}

\section{Economic aspects}

Straw substrate was the cheapest substrate used in our experiment to cover the pen floor (10-cm thick). The cellulose bedding, which initially seemed to be the newest substrate, had a higher price per kilogram than straw. However, as it is sold baled, the higher initial price is compensated by cheaper transportation costs. The main problem with the cellulose substrate is low availability as it is not normally available on the commercial market, although it is normally used as bedding in aviculture. An important advantage of this substrate is that it is recycled from the paper industry (LER030310). On the other hand, the amount of straw used $\left(\mathrm{kg} / \mathrm{m}^{2}\right)$ was less than the other bedding materials, which would promote its use as a more economic alternative, where it is available. From the point of view of availability in the Spanish market, straw is the most available, followed by rice husk (Aragón produces large amounts of those cereals). It should be underlined that the prices used in our study may vary significantly depending on the market. For example, at that time of the experiment, the price of the sawdust substrate 
was quite high because of the national crisis in the building industry (of which sawdust is a by-product).

\section{Behavior measures}

Although previous works have already reported less stereotypic behaviors in the lambs on straw bedding than those on slats (Cooper and Jackson, 1996) or without any bedding substrate (Teixeira et al., 2012), the results of the present study also suggest that straw bedding can minimize the frequency of stereotypic behavior compared to other bedding substrates. However, these abnormal behaviors decreased throughout fattening, and the differences between treatments disappeared halfway through the finishing stage. In our study, the most apparent cause of stereotypies may be related to the lack of stimulation and the initial social conditions at the beginning of the study. After the first few days of fattening, stereotypic behaviors dropped to less than half, for all the substrates, although a slight increase was observed toward the end of finishing, probably because of the influence of other types of intermittent, low-intensity environment stressors.

The substrate that aroused the most exploratory behavior in lambs was cellulose, which is not in accordance with their clear preference for sawdust when all substrates are available simultaneously (Teixeira et al., 2013). Initially, straw bedding also awakened great interest in the animals but it dropped off suddenly toward the mid point of the finishing stage. That is possibly because straw quickly changes its chemical and microbiological characteristics throughout the finishing stage (Teixeira et al., 2014). Sawdust and rice husk produced an average level of interest that increased slightly over the fattening period. To our knowledge, no studies have considered the interaction among lambs using different types of bedding substrates.

The same decreasing tendency observed in stereotypic behaviors throughout fattening was also observed in relation to agonistic interactions. However, in this case, there were no initial differences between substrates, probably because the lambs had been regrouped (Miranda-de la Lama et al., 2012). The affiliative behavior recorded throughout the fattening stage was greater at the beginning and middle of the trial, with the exception of the straw treatment, where it remained constant throughout the whole period and was less frequent than other substrates on day 1 and 12 . Although a treatment with no bedding substrate was not included in this study, it seems that the lambs reared on all 4 substrates displayed less agonistic and more affiliative behaviors at the beginning of the study than those without bedding substrate evaluated in the study of Teixeira et al. (2012). That comparison suggests a lower biological cost of adaptation to finishing pens when bedding is present.

\section{Physiological measures}

In our study, cortisol levels were higher for lambs housed on sawdust and lowest for those housed on straw. The other 2 bedding materials had intermediate levels. In general, cortisol levels remained within a similar range throughout the fattening stage, which indicates that the initial stressors (transportation, classification, and new environment) were followed by low-intensity, intermittent stressors, probably resulting from the finishing environment itself. Although cortisol levels were high in relation to the basal levels for the species (Cook, 1996), they did not represent a strong stress response with a high biological cost (Hargreaves and Hutson, 1990). Apple et al. (1995) studied the effect of isolation in lambs with much higher cortisol levels, even in control animals (approximately $35 \mathrm{ng} / \mathrm{mL}$ ). However, we have to consider possible breed differences. The Rasa Aragonesa is a typical Mediterranean breed well adapted to an agroecosystem that combines extensive (breeding phase) and intensive (fattening stage) phases.

Stress increases the levels of circulating adrenaline, inducing catabolism of muscle glycogen to be used in the liver for gluconeogenesis, which increases glucose and lactate levels (Apple et al., 1995). Therefore, energy-related variables should be included to assess animal welfare in stressful situations such as handling and poor quality facilities. In relation to these energy indicators, in our study, we observed slight differences between treatments for lactate and glucose. The lambs on cellulose bedding had lower lactate levels on day 1 than on day 8 , and those on straw bedding had higher glucose on day 1 than on day 8. Teixeira et al. (2012), studying the same type of lambs, reported higher levels of glucose and lactate for animals without any bedding substrate compared with those on straw. Furthermore, the findings reported by Teixeira et al. (2012) seem to be higher than the levels of glucose and lactate found for the lambs on any of the 4 bedding substrates assessed in the present study after 1 week of fattening. Again, the slight differences that we found for these indicators were always within the ranges normally observed for low-intensity stressors (Dubreuil et al., 2005). From the physiological results obtained, we can deduce that none of the substrates used provoked high levels of stress. Barnett and Hemsworth (1990) suggest that an increment of $>40 \%$ in basal glucose levels indicates a negative effect on animal welfare. However, in the present study, glucose concentration did not exceed $10 \%$ of the basal levels for animals of this category.

Chronic stress situations can lead to a state of immunodepression that can be evaluated by examining the N/L ratio. In our study, the $\mathrm{N} / \mathrm{L}$ ratio suggested little immunodepression of lambs in any of the substrates analyzed. Only the animals on cellulose showed a slightly higher N/L ratio but below levels that could be considered to pose a health risk. In fact, none of the lambs showed any clinical signs of illness. However, it should be noted that the fattening period considered was quite short. In a longer fattening period with heavier lambs, bedding conditions may have had more of an effect on lamb health. Similarly, Teixeira et al. (2012) found no significant differences in the N/L ratio between treatments (straw bedding vs. without any bedding substrate).

With regard to the hematologic data, apart from the N/L ratio already mentioned, no large differences were observed for red or white blood cells being within accepted ranges for clinically healthy animals (Kaneko et al., 1997). Hematocrit values were slightly higher in lambs on rice husk bedding and lower in those on sawdust. However, the difference between the highest and lowest values was no more than $15 \%$, which does not imply dehydration, which tends to increase with stress, such as during transport (Knowles, 1998).

In response to an acute environmental challenge, animals display the fight or fight response, increasing their muscular activity. During vigorous exercise, muscle may get damaged or fatigued, releasing the CK enzyme into the blood (Knowles et al., 1998; Van de Water et al., 2003). As a result, plasma CK is generally considered an indicator of physical stress because of intense activity to cope with environmental challenges. Although there was a decreasing tendency for sawdust lambs, the values observed for lambs in the 4 bedding materials are within normal ranges for the species (Dubreuil et al., 2005). On the other hand, Teixeira et al. (2012), studying the same type of lambs, reported higher CK levels for lambs fattened without any bedding substrate.

\section{Productive performance and meat quality}

Stressful episodes caused by poor environmental conditions during the finishing phase of fattening can decrease the performance of feedlot animals (Hahn, 1994). Management strategies 
(e.g., providing proper bedding substrates) to decrease or alleviate stress-related production losses are warranted. The lambs from all 4 substrates in our study displayed acceptable productive performance within expected ranges for this lamb category. From that point of view, all 4 substrates could be successfully included in the production system. Thus, depending on cost and availability, farmers have valid and efficient options to make the right decision in each situation.

In general, the production data were much better than those recorded by Wolf et al. (2010), who found increases of between 130 and 150 grams daily, without finding significant differences between the 2 types of substrates tested. However, that study used breeds of lambs with older chronological and physiological ages than in our study. On the other hand, Fluharty et al. (1999) found that lambs housed on straw bedding grew faster than those housed on sand, but they did not find any differences in the consumption of dry matter or conversion efficiency. Their average daily growths are similar to our study, but they used British lambs with a higher slaughter weight.

In our study, there were no differences in carcass performance between lambs fattened on the 4 types of substrate. Neither did we observe any differences for cold carcass weight, carcass conformation, or fatness. There were also no differences in the prevalence of hematoma on the carcasses. Of all of the meat quality parameters that are usually analyzed, $\mathrm{pH}_{\mathrm{ult}}$ is perhaps the most important. There were no differences between treatments for this variable, and the $\mathrm{pH}$ was always within the range established for commercially optimum meat (Gregory, 2007). Nevertheless, there are studies that show that stressful situations such as isolation or confinement may cause significant reductions in glycogen reserves in muscles, producing meat with $\mathrm{pH}_{\text {ult }}$ values $>6$, resulting in dark meat (Apple et al., 1995). The color of the meat from animals housed on the 4 types of substrates was normal, in line with the known characteristics of Ternasco-type lambs (Ripoll et al., 2008).

\section{Conclusions}

The results of our study suggest that the bedding substrate affected lamb behavior during the adaptation to a new physical and social environment in the finishing phase of fattening. The lambs on cellulose manipulated it more. There were no significant differences in the stress response with regard to substrate. All substrates evaluated could be efficiently incorporated into the system as bedding material without affecting productivity or product quality. At this moment, straw is the best option for bedding as it preserves lamb welfare and guarantees performance and product quality at a lower cost, but cellulose may be a competitive and more sustainable option in the future as it becomes more available on the market.

\section{Acknowledgments}

Funding was provided by the Ministry of Economy and Competitiveness (CICYT) of Spain (projects AGL-2008/02088 and AGL2009/10794). The study was approved by Comisión Etica Asesora of the University of Zaragoza (www.unizar.es). The authors acknowledge the collaboration of the Pastores Cooperative Group (Oviaragón) and the meat processing plant Mercazaragoza. The authors thank the University Service for Animal Experimentation (SEA) and to the Meat Quality and Technology Group of the University of Zaragoza. The authors also thank the Santander Central Hispano Bank and the University of Zaragoza for the Latin American Scholarship Ph.D. Program for Dr. Dayane Lemos Teixeira.

The idea for the study was conceived by Gustavo Adolfo Maria and Dayane Lemos Teixeira. The experiments were designed by
Gustavo Adolfo Maria. The experiment was performed by Dayane Lemos Teixeira, Gustavo Adolfo María, and Genaro Miranda de la Lama. The data were analyzed by Gustavo Adolfo Maria, Dayane Lemos Teixeira, and Morris Villarroel. The article was written by Dayane Lemos Teixeira, Gustavo Adolfo Maria, and Morris Villarroel.

\section{Conflict of interest}

The authors declare no conflict of interest.

\section{References}

Apple, J.K., Dikeman, M.E., Minton, J.E., McMurphy, R.M., Fedde, M.R., Leith, D.E. Unruh, J.A., 1995. Effects of restraint and isolation stress and epidural blockade on endocrine and blood metabolite status, muscle glycogen metabolism, and incidence of dark-cutting longissimus muscle of sheep. J. Anim. Sci. 73, 2295-2307.

Barnett, J.L., Hemsworth, P.H., 1990. The validity of physiological and behavioural measures of animal welfare. Appl. Anim. Behav. Sci. 25, 177-187.

Chacón, G., Garcia-Belenguer, S., Ilguera, J.C., Palacio, J., 2004. Validation of an EIA technique for the determination of cortisol. Span. J. Agric. Res. 2, 45-51.

CIE, 1976. Commission Internationale de I_Eclairage, 18th session, London, UK, September 1975. CIE, London, UK, p. 36.

Cook, C.J., 1996. Basal and stress response cortisol levels and stress avoidance learning in sheep (Ovis ovis). N. Z. Vet. J. 44, 162-163.

Cooper, J., Jackson, R., 1996. A comparison of the feeding behaviour of sheep in straw yards and on slats. Appl. Anim. Behav. Sci. 49, 99.

Dubreuil, P., Arsenault, J., Bélanger, D., 2005. Biochemical reference ranges for groups of ewes of different ages. Vet. Rec. 156, 636-638.

Ericsson, K., Nilsson, L.J., 2006. Assessment of the potential biomass supply in Europe using a resource-focused approach. Biomass Bioenerg. 30, 1-15.

European Union, 1993. EEC Lamb Carcass Classification System Regulations, Number: 2137/92 and 461/93. Office for Official Publications of the European Communities, Luxembourg. L-2985.

Fluharty, F.L., Lowe, G.D., Clevenger, D.D., 1999. Effects of Pen Floor Type and Bedding on Lamb Growth and Carcass Characteristics. Research and Reviews: Beef and Sheep. Special Circular 170-99. College of Food, Agricultural and Environmental Sciences, Ohio State University. Available at: http://ohioline. osu.edu/lines/bulls.html.

Gauder, M., Graeff-Hönninger, S., Claupein, W., 2011. Identifying the regional straw potential for energetic use on the basis of statistical information. Biomass Bioenerg. 35, 1646-1654.

Gregory, N.G., 2007. Animal Welfare and Meat Production. CABI, Wallingford, UK.

Hahn, G.L., 1994. Environmental requirements of farm animals. In: Griffiths, J.F. (Ed.), Handbook of Agricultural Meteorology. Oxford University Press, New York, pp. 220-235.

Hargreaves, A.L., Hutson, G.D., 1990. The stress response in sheep during routine handling procedures. Appl. Anim. Behav. Sci. 26, 83-90.

Kaneko, J.J., Harvey, J.W., Bruss, M.L., 1997. Clinical biochemistry of domestic animals. Academic Press, San Diego. Appendix VII.

Knowles, T.G., 1998. A review of the road transport of slaughter sheep. Vet. Rec. 143 212-219.

Knowles, T.G., Warriss, P.D., Brown, S.N., Edwards, J.E., 1998. Effects of stocking density on lambs being transported by road. Vet. Rec. 142, 503-509.

Martin, P., Bateson, P., 1993. Measure of Behaviour. Measuring Behaviour: An Introductory Guide. Cambridge University Press, Cambridge, UK, pp. 62-83.

Mason, G., Rushen, J., 2008. Stereotypic Animal Behaviour: Fundamentals and Applications to Welfare, 2nd edn. CAB International, Wallingford, UK.

Miranda-de la Lama, G.C., Villarroel, M., María, G.A., 2012. Behavioural and physiological profiles following exposure to novel environment and social mixing in lambs. Small Rumin. Res. 103, 158-163.

Norring, M., Manninen, E., de Passillé, A.M., Rushen, J., Saloniemi, H., 2010. Preferences of dairy cows for three stall surface materials with small amounts of bedding. J. Dairy Sci. 93, 70-74.

Ripoll, G., Joy, M., Muñoz, F., Albertí, P., 2008. Meat and fat colour as a tool to trace grass-feeding systems in light lamb production. Meat Sci. 80, 239-248.

Sañudo, C., Santolaria, M.P., María, G., Osorio, M., Sierra, I., 1996. Influence of carcass weight on instrumental and sensory lamb meat quality in intensive production systems. Meat Sci. 42, 195-202.

SAS, 1988. SAS/SAT User's Guide. Statistics Analysis Institute, Cary, NC, USA.

Spoolder, H.A.M., De Bree, J., Van der Mheen, H.W., Bracke, M.B.M., 2003. Not animal related but housing parameters determine an expert's intuitive welfare assessment of pig farms. In: Ferrante, F., Canali, E., Carenzi, C., Mattiello, S. Minero, M., Palestrini, C., Tosi, M.V., Verga, M. (Eds.), 37th Intern. Congr. ISAE, Abano Terme, Italy.

Swanson, J.C., 1995. Farm animal well-being and intensive production systems. J. Anim. Sci. 73, 2744-2751. 
Teixeira, D.L., Miranda-de la Lama, G.C. Villarroel, M., Garcia-Belenguer, S., Sañudo, C., María, G.A., 2012. Effect of straw on lamb welfare, production performance and meat quality during the finishing phase of fattening. Meat Sci. 92, 829-836.

Teixeira, D.L., Miranda-de la Lama, G., Pascual-Alonso, M., Aguayo-Ulloa, L. Villarroel, M., María, G.A., 2013. A note on lamb's choice for different types of bedding materials. J. Vet. Behav.: Clin. Appl. Res. 8, 175-179.

Teixeira, D.L., Villarroel, M., María, G.A., 2014. Assessment of different organic bedding materials for fattening lamb. Small Rumin. Res. 119, 22-27.
Tuyttens, F.A.M., 2005. The importance of straw for pig and cattle welfare: A review. Appl. Anim. Behav. Sci. 92, 261-282.

Van de Water, G., Verjans, F., Geers, R., 2003. The effect of short distance transport under commercial conditions on the physiology of slaughter calves; $\mathrm{pH}$ and colour profiles of veal. Livest. Prod. Sci. 82, 171-179.

Wolf, B.T. Molloy, H.R.B., Trayte, M.J., Rose, M.T., 2010. Behaviour of growing lambs housed on straw or woodchip bedding materials and their preference for floor type. Appl. Anim. Behav. Sci. 124, 45-50. 